\title{
Corrigenda: Premna bhamoensis (Lamiaceae, Premnoideae), a new species from Kachin State, northeastern Myanmar
}

\author{
Yunhong Tan ${ }^{1,2}$, Derong $\mathrm{Li}^{3}$, Yongjun $\mathrm{Chen}^{3}$, $\mathrm{Bo} \mathrm{Li}^{3}$
}

I Southeast Asia Biodiversity Research Institute, Chinese Academy of Sciences, Yezin, Nay Pyi Taw 05282, Myanmar 2 Center for Integrative Conservation, Xishuangbanna Tropical Botanical Garden, Chinese Academy of Sciences, Mengla, Yunnan 666303, China 3 College of Agronomy, Jiangxi Agricultural University, Nanchang, Jiangxi 330045, China

Corresponding author: Bo Li (hanbolijx@163.com)

Academic editor: Y. Mutafchiev | Received 4 August 2017 | Accepted 7 August 2017 | Published 31 August 2017

Citation: Tan Y, Li D, Chen Y, Li B (2017) Corrigenda: Premna bhamoensis (Lamiaceae, Premnoideae), a new species from Kachin State, northeastern Myanmar. PhytoKeys 85: 125-125. https://doi.org/10.3897/phytokeys.85.19983

A new Premna species, named as Premna bhamoensis Y.T. Tan \& B. Li, was recently described in Tan et al. (2017), however an overlooked spelling error emerged in the authorship of this new species. The name abbreviation of the first author, Yunhong Tan, should be Y. H. Tan, not as originally published Y.T. Tan. Here we correct the authorship of Premna bhamoensis as Y.H. Tan \& B. Li.

\section{References}

Tan Y, Li D, Chen Y, Li B (2017) Premna bhamoensis (Lamiaceae, Premnoideae), a new species from Kachin State, northeastern Myanmar. PhytoKeys 83: 93-101. https://doi.org/10.3897/ phytokeys.83.12869

Copyright Yunhong Tan et al. This is an open access article distributed under the terms of the Creative Commons Attribution License (CC BY 4.0), which permits unrestricted use, distribution, and reproduction in any medium, provided the original author and source are credited. 